https://doi.org/10.47370/2078-1024-2021-13-2-41-47

УДК 378: 316.74

Бибикова Э.В.

РОЛЬ ИНОЯЗЫЧНОЙ ПРОФЕССИОНАЛЬНОЙ КОММУНИКАЦИИ В ПОДГОТОВКЕ СОВРЕМЕННОГО СПЕЦИАЛИСТА В НЕЯЗЫКОВОМ ВУЗЕ

\author{
Бибикова Эльвира Витальевна, \\ кандидат педагогических наук, дочент кафедры иностранных языков \\ ФГБОУ ВО «Майкопский государственный технологический универси- \\ тет», Майкоп, Россия, \\ e-mail: elvira-01@mail.ru
}

\begin{abstract}
Аннотация
Актуальность данного исследования обусловлена тем, что в условиях расширения международных контактов, установления отношений с зарубежными партнерами значительно возрастает роль профессиональной иноязычной коммуникации. Целью исследования является обоснование значимости иностранного языка при подготовке современного специалиста в неязыковом вузе. ФГОС ВО требует учитывать профессиональную специфику при изучении языка. Иностранный язык рассматривается не как обособленный, самостоятельный предмет, а как дисциплина, позволяющая приобрести специальные знания терминологии по выбранной специальности. Проблема современных специалистов заключается в том, что низкий уровень иноязычной грамотности может существенно снизить их конкурентоспособность на рынке труда. В связи с этим профессионально-ориентированное обучение иностранным языкам является приоритетным направлением в современном образовании. Опираясь на собственный опыт преподавания, автор подчеркивает, что профессионально-ориентированные тексты легче справляются с вопросом повышения мотивации к изучению иностранного языка. На примере учебного пособия для бакалавров «Hoticultural and Landscape Design in English» автор знакомит с тематическими разделами и методами, которые использует в процессе работы с обучающимися по направлению подготовки «Ландшафтная архитектура». При отборе материала для учебного пособия по иностранному языку преподаватель может столкнуться с определенными трудностями. В статье приводятся способы решения данной проблемы. В ходе работы автором проанализирована научная литература по заявленной тематике. В работе используются методы наблюдения, сравнения, анализа.

В результате исследования показано, что дисциплина «иностранный язык» является необходимым компонентом в процессе подготовки специалиста любого профиля.

Ключевые слова: иноязычная профессиональная коммуникация, конкурентоспособность, профессионально-ориентированное обучение, иностранный язык, неязыковой вуз, мотивация, профессиональная лексика, специалист.
\end{abstract}

Для цитирования: 'Бибикова Э.В. Роль иноязычной профессиональной коммуникации в подготовке современного специалиста в неязыковом вузе // Вестник Майкопского 
государственного технологического университета. 2021. Том 13, № 2. C. 41-47. https:// doi.org/10.47370/2078-1024-2021-13-2-41-47.

Bibikova E.V.

\title{
THE ROLE OF FOREIGN LANGUAGE PROFESSIONAL COMMUNICATION IN A MODERN SPECIALIST'S TRAINING IN A NON-LINGUISTIC UNIVERSITY
}

\author{
Bibikova Elvira Vitalyevna, \\ Candidate of Pedagogics, an associate professor of the Department of Foreign Lan- \\ guages of FSBEI HE "Maykop State Technological University", Maykop, Russia, \\ e-mail: elvira-01@mail.ru
}

\begin{abstract}
Annotation
The relevance of the research stems from the fact that the role of professional foreign language communication is significantly increasing in the context of expanding international contacts, establishment of relations with foreign partners. The purpose of the research is to substantiate the importance of a foreign language in the process of a modern specialist's training in the non-linguistic university. FSES demands professional specifics when learning a language. A foreign language is considered not as a separate, independent discipline, but as the one allowing to acquire special knowledge of terminology in a selected area.

The problem of modern specialists is that the low level of foreign language literacy can significantly reduce their competitiveness in the labor market. In this regard, professional-oriented training in foreign languages is a priority direction in modern education. Relying on their own teaching experience, the author emphasizes that professional-oriented texts are easier to cope with the issue of improving motivation to the study of a foreign language. Using a tutorial for bachelors "Horticultural and Landscape Design in English", the author introduces thematic sections and methods used in working with "Landscape architecture" students. When selecting a material for a textbook in a foreign language, a teacher may face certain difficulties. The article provides ways to solve this problem. The author has analyzed scientific literature on the stated topics. Methods of observation, comparison, analysis have been used.

It has been concluded that foreign language is a necessary component in the process ofitraining a specialist ofiany profile.

Keywords: foreign language professional communication, competitiveness, professional-oriented training, a foreign language, a non-language university, motivation, professional vocabulary, a specialist.

For citation: 'Bibikova E.V. The role of foreign language professional communication in a modern specialist's training in a non-linguistic university // Vestnik Majkopskogo gosudarstvennogo tehnologiceskogo universiteta. 2021. Volume 13, No. 2. P. 41-47. https:/doi. org/10.47370/2078-1024-2021-13-2-41-47.
\end{abstract}

«Кто не умеет говорить, тот карьеры не сделает»

(Наполеон Бонапарт)

Жизнь человека невозможно представить без такого процесса как коммуникация. Появившись на свет, он тут же вступает в коммуникативные взаимоотношения с окружающим его миром. Ни одна из сфер нашей жизнедеятельности 
невозможна без коммуникации. По сути, коммуникация является способом и средством существования человека. Термин «коммуникация» происходит от латинского слова communicatio - coобщение, передача. Но с течением времени первоначальное значение термина несколько изменилось и в настоящее время он трактуется весьма широко. В словарях дается великое множество определений данного термина. Например, в «Новом словаре иностранных слов» («оммуникация» - это 1) путь сообщения (напр., воздушная к., водная к.); 2) форма связи (напр., телеграф, радио, телефон); 3) акт общения, связь между двумя или более индивидами, основанные на взаимопонимании; сообщение информации одним лицом другому или ряду лиц; 4) массовая коммуникация процесс сообщения информации с помощью технических средств [1].

В данной статье термин «коммуникация» интересует нас как акт общения. В процессе своей жизнедеятельности люди взаимодействуют друг с другом, используя язык. Язык - это самое древнее и главное свойство человека, которое отличает его от других живых существ. В.В. Крюков отмечает, что язык представляет собой систему знаков, служащую средством человеческого общения и мыслительной деятельности, способом выражения самосознания личности, средством хранения и передачи социальной информации [2]. Язык обладает множеством важных функций, но основными считаются следующие: коммуникативная (язык является важнейшим средством общения, обмена мыслями, передачи различной информации), аккумулятивная (способствует накоплению, хранению и передаче знаний и информации последующим поколениям), номинативная (с помощью языка человек называет предметы и явления) и когнитивная (способствует вербализации мышления, обеспечивает познание и ориентацию в мире). Кроме всего этого язык отражает национальный характер, менталитет, традиции, обычаи, образ жизни, мораль, общественное самосознание народа. Он способствует формированию личности носителя языка.

Среди разнообразных видов коммуникации следует выделить профессиональную коммуникацию или деловое общение. Люди ежедневно сталкиваются с профессиональным общением. Целью профессиональной коммуникации является эффективное взаимодействие сотрудников организации, предприятия или компании. Именно этот вид общения способен объединить и согласовать людские усилия, направленные на урегулирование взаимоотношений и получение общего результата. От быстроты и доступности передачи информации, от слаженных действий коллектива очень часто зависит качество и темп работы всего предприятия или компании. Но современные условия жизни предъявляют новые требования к специалистам. Процесс всемирной интеграции с каждым днем охватывает все больше стран и народов и поэтому профессионалы должны уметь осуществлять коммуникацию не только на родном языке, но должны уметь делать это и на иностранном языке. Такие специалисты имеют явные преимущества перед своими «безъязычными» конкурентами при приеме на работу. Работодатели стали отдавать предпочтение тем, кто способен быстро находить и извлекать нужную информацию из иностранных источников, доступно излагать ее на родном языке, а затем умело использовать в своей работе. Из этого следует сделать вывод, что конкурентоспособность специалиста на рынке труда во многом зависит от того, насколько хорошо он владеет иностранным языком. Все эти моменты, в свою очередь, существенно повышают значимость иностранных языков при подготовке специалистов в неязыковых вузах. В федеральных государственных 
образовательных стандартах высшего образования делается акцент на профессиональную составляющую в процессе изучения дисциплины «Иностранный язык». Владение иностранным языком для специалиста любого профиля является огромным плюсом, так как в настоящее время язык рассматривают уже не как отдельную дисциплину, а как инструмент для получения специальных знаний терминологии по выбранной специальности [3]. Изучение иностранного языка является одним из важных условий прогресса, поскольку язык используется для приобретения знаний и опыта других стран и умения использовать их во благо своей страны. На успешное экономическое развитие России в целом и ее представителей частного бизнеса огромное влияние оказывает интеграционная роль иностранного языка. Профессионалы, владеющие языком международного общения, становятся наиболее востребованными специалистами в различных сферах деятельности. Как отмечает Е.И. Пассов, низкий уровень иноязычной грамотности специалистов не только подрывает конкурентоспособность нашего государства, но и мешает экономике внутри страны. Особенно заметно это проявляется при организации совместных предприятий, где партнеры должны хорошо знать друг друга, без чего нет доверия. Самый большой барьер к узнаванию друг друга - языковой. Руководители зарубежных фирм давно поняли это. Они не только сами владеют несколькими языками, но и стремятся к тому, чтобы каждый рабочий знал хотя бы один иностранный язык [4]. Конструктивное общение с иностранными коллегами обусловливает необходимость владения соответствующим иностранным языком и/ или языком международного общения, каковым сегодня повсеместно признается английский язык. Таким образом, объективно повышается значимость иноязычной подготовки для становления профессиональной компетентности специалистов. Поэтому в неязыковых вузах при подготовке специалистов с высшим образованием такой предмет, как иностранный язык, на наш взгляд, следует включить в перечень обязательных дисциплин.

Основной задачей обучения иностранному языку студентов неязыковых вузов в современных условиях является формирование иноязычной коммуникативной компетенции, которая в свою очередь позволяет свободно ориентироваться в иноязычной среде и тем самым способствует формированию конкурентоспособного специалиста на рынке труда. В современных условиях иноязычное общение становится существенным компонентом будущей профессиональной деятельности специалиста [5]. Британский лингвист и социолог Д. Грэддол считает, что иностранный язык все реже будет преподаваться в качестве самостоятельной дисциплины, так как он является средством преподавания учебных предметов через язык. Он также говорит о том, что преподаватели иностранного языка должны работать в тесном контакте с преподавателями специальных дисциплин [7]. В данном контексте можно говорить о приоритетности профессионально-ориентированного обучения иностранным языкам в высшей школе в сравнении с другими существующими методиками. Этот вид обучения учитывает особенности будущей профессии, способствует формированию иноязычного общения в определенных профессиональных ситуациях, а также научных и деловых сферах. Данный вид обучения предполагает новый подход к отбору содержания. Так, например, в учебное пособие «Hoticultural and Landscape Design in English» для обучающихся по направлению подготовки бакалавров 35.03 .10 «Ландшафтная архитектура» нами были включены следующие тексты с учетом специфики будущей специальности: 
«История ландшафтной архитектуры» (History of landscape architecture), «Регулярный сад» (The French formal garden), «Пейзажный сад» (English garden), «Дзен сад» (Zen garden), «Гайд-парк в Лондоне» (Hyde Park in London), «Садовый пруд» (Garden pond), «Озеленение крыш» (Green roof), «Садовые сорняки» (Garden Weeds), «Декоративные растения» (Ornamental Plants) и т.п. Так как все тексты имеют профессиональную направленность, то вопроса о повышении мотивации к изучению иностранного языка, как правило, не возникает. Из практики преподавания языка можно отметить, что интерес к предмету возрастает тогда, когда он имеет практическое значение, когда обучающиеся четко и ясно видят перспективы использования полученных знаний, когда целью обучения становятся полезные навыки и умения, которые в будущем будут иметь ценность и повысят личную конкурентоспособность и шансы на успех в выбранной сфере деятельности. Современный мир предоставляет массу возможностей для самореализации личности при условии, что человек обладает определенным набором качеств, умений и является конкурентоспособным специалистом. Владение иностранным языком (а иногда и нескольким языками) всё чаще является одним из требований работодателей, поэтому и мотивировать обучающихся стало проще. Молодые люди стали сами осознавать значимость данного предмета в их профессиональной подготовке.

Но такое отношение к иностранному языку у обучающихся складывается не сразу. Чтобы выяснить, видят ли молодые люди в иностранном языке предмет, способный помочь им в профессиональной сфере, нами были проведены два опроса в 2019 - 2020 учебном году. В них приняли участие обучающиеся первого курса экологического факультета по направлению подготовки бакалавров «Ландшафтная архитектура» Майкопского государственного технологического университета. Первый опрос проводился в начале 1 семестра (в сентябре), а второй - в конце 2 семестра (в мае). Обучающимся было предложено ответить на один и тот же вопрос: «Помогает ли знание иностранного языка в приобретении профессиональных навыков и умений?» В опросе участвовало 43 респондента. В сентябре отрицательно ответило 27 респондентов, что составило $63 \%$ от общего числа. В мае утвердительно ответило 39 респондентов или $91 \%$ от общего числа опрошенных. Результаты опроса подтверждают, что именно профессионально-ориентированный подход в обучении позволяет увидеть в дисциплине «иностранный язык» инструмент, с помощью которого можно получить дополнительные знания по специальности.

Приведем примеры работы и итоговых заданий по темам «Дзен сад» (Zen garden) и «Гайд-парк в Лондоне» (Hyde Park in London). В процессе работы над темами был выполнен рад упражнений, направленных на формирование профессионального тезауруса. Работа над основными текстами разделов проводилась в три этапа: предтекстовый, текстовый и послетекстовый. Каждый из этапов включал определенный набор упражнений, направленных на снятие трудностей в понимании нового текста (предтекстовый этап), проверку понимания прочитанного (текстовый этап), формирование умений по использованию полученной информации в профессиональной деятельности (послетекстовый этап). Итоговым заданием по первой теме было создание миниатюрного сада Дзен (a small-scale version of Zen garden). Обучающиеся должны были подготовить весь необходимый материал и создать свой Дзен сад. Процесс создания сада необходимо было зафиксировать на видео. В аудитории обучающиеся не просто демонстрировали свои ролики, а подробно озвучивали их на языке. По итогам 
работы над второй темой обучающиеся должны были подготовить и провести экскурсию по Гайд-парку. Они составляли индивидуальные маршруты по парку с посещением и подробным описанием наиболее интересных арт-объектов с их точки зрения. Так как парк огромный и таких объектов в нем много, каждый выбирал самостоятельно не менее пяти мест. Экскурсии были представлены в формате презентации Power Point. Эти виды работ вызвали огромный интерес у присутствующих. Молодые люди смогли продемонстрировать полученные профессиональные навыки и умения.

Но при отборе материала для учебного пособия у преподавателя, ведущего занятия по иностранному языку, могут возникнуть определенные сложности. В силу своего лингвистического либо педагогического образования он не владеет специальной профессиональной терминологией. Для решения данной проблемы преподавателю иностранного языка следует изучить базовую профессиональную лексику, основы специальности, пообщаться с преподавателями, которые ведут специальные дисциплины, а лучше посетить их занятия. На наш взгляд, целесообразно использовать материалы, дающие первоначальные понятия специальности, так как преподаватели профилирующих дисциплин не всегда уделяют этому достаточно внимания. Также можно воспользоваться помощью преподавателя-предметника при проведении занятия (так называемое «преподавание в команде» [6]).

В заключение хотелось бы отметить, что знание иностранного языка повышает конкурентоспособность выпускника вуза и влияет на его дальнейший карьерный рост. Таким образом, иностранный язык как учебный предмет является важным компонентом в процессе подготовки современного специалиста.

\section{ЛИТЕРАТУРА:}

1. [Электронный ресурc]. URL: https://slovar.cc/rus/inostr-nov.html

2. Крюков В.В. Язык как знаковая система и ценность общения [Электронный ресурс] // Идеи и идеалы. 2016. № 4 (30). URL: https://cyberleninka.ru/article/n/yazyk-kak-znakovayasistema-i-tsennost-obscheniya (дата обращения: 01.02.2021).

3. Фуфурина Т.А. Изучение иностранного языка для профессиональных целей как успех будущей карьеры студентов технических вузов // Наука, техника и образование. 2015. № 2 (8). С. $98-103$.

4. Пассов Е.И. Программа-концепция коммуникативного иноязычного образования «Развитие индивидуальности в диалоге культур». М.: Просвещение, 2000. 172 с.

5. Бибикова Э.В. Особенности профессионально-ориентированного обучения иностранному языку в неязыковом вузе [Электронный ресурс] // О некоторых вопросах и проблемах психологии и педагогики: сборник научных трудов по итогам международной научно-практической конференции (Красноярск, 11 ноября 2016 г.). URL: https://elibrary.ru/item.asp?id=28428226

6. Кучерявая Т.Л. Проблемы профессионально-ориентированного обучения иностранному языку студентов неязыковых специальностей [Электронный ресурс] // Теория и практика образования в современном мире: материалы I Международной научной конференции (г. Санкт-Петербург, февраль 2012 г.). Т. 2. СПб.: Реноме, 2012. C. 336-337. URL: https://moluch. ru/conf/ped/archive/21/1783/ (дата обращения: 08.03.2021).

7. Graddol D. English Next. London: British Council, 2006. 132 p.

\section{REFERENCES:}

1. [Electronic resource]. URL: https://slovar.cc/rus/inostr-nov.html 
2. Kryukov .V.V. Language as a sign system and value of communication [Electronic resource] // Ideas and ideals. 2016. No. 4 (30). URL: https://cyberleninka.ru/article/n/yazyk-kak-znakovayasistema-i-tsennost-obscheniya (date of access: 01.02. 2021).

3. Fufurina T.A. Studying a foreign language for professional goals as a success of the future career of students of technical universities // Science, appliances and education. 2015. № 2 (8). P. 98-103.

4. Passov E.I. The program-concept of communicative foreign language education "Development of individuality in the dialogue of cultures". M.: Prosveshchenie, 2000. 172 p.

5. Bibikova E.V. Features of professional-oriented foreign language learning in a non-linguistic university [Electronic resource] // On some issues and problems of Psychology and Pedagogy: a collection of scientific works of the international scientific and practical conference (Krasnoyarsk, November 11, 2016). URL: https://elibrary.ru/item.asp?id=28428226.

6. Kucheryavaya T.L. Problems of professional-oriented foreign language learning of nonlinguistic students [Electronic resource] // Theory and practice of education in the modern world: materials of I International Scientific Conference (St. Petersburg, February 2012). V. 2. SPB: Renome, 2012. P. 336-337. URL: https://moluch.ru/conf/ped/archive/21/1783/ (date of access: 08.03.2021).

7. Graddol D. English Next. London: British Council, 2006. 132 p. 